\title{
Shielding effectiveness measurements and uncertainty estimation for textiles by a VNA-based free space transmission method
}

\author{
S.M. Patel ${ }^{1, \star}$, K. Patel ${ }^{2}$, P.S. Negi ${ }^{3}$, and V.N. Ojha ${ }^{1}$ \\ 1 Quantum Phenomenon and Applications, CSIR-National Physical Laboratory, Dr. K.S. Krishnan Road, New Delhi-12, India \\ 2 Silicon Thin Film Solar Cells, CSIR-National Physical Laboratory, Dr. K.S. Krishnan Road, New Delhi-12, India \\ 3 Electrical Standards, CSIR-National Physical Laboratory, Dr. K.S. Krishnan Road, New Delhi-12, India
}

Received: 23 April 2013 / Accepted: 12 July 2013

\begin{abstract}
A free-space transmission method has been used for reliable shielding effectiveness measurement of the easily available textile materials. Textiles with three different yarn densities were studied for their shielding effectiveness with the help of a vector network analyzer and laboratory calibrated two X-band horn antennas. The expressions of uncertainty estimation have been derived in accordance with the present free-space measurement setup for the calculated SE values. The measurements have shown that an electromagnetic energy can be maximum shielded up to $16.24 \mathrm{~dB}$ with measurement uncertainty less than $0.21 \mathrm{~dB}$ in 8.2 to $12.4 \mathrm{GHz}$ range by a $160.85 \mu \mathrm{m}$ textile. Thus, a thin textile with a high density can have higher shielding and this property mainly depends on its intrinsic structure, frequency range and thickness. This study promises the potential applications of such materials as a very cost effective shielding material at microwave frequencies with some modifications.
\end{abstract}

Keywords: Shielding property; measurement uncertainty; free-space transmission method; VNA; $S$-parameter

Nomenclature: Microwave measurement, RF metrology, Material characterization.

\section{Introduction}

Due to wider applications of electrical and electronic equipments almost everywhere, there is a presence of electromagnetic energy in different strengths. This energy travels in a unified transmission medium or as a radiant and exposed to the other equipments or person in its environs. So in general, an electromagnetic interference (EMI) is the disruption of operation of an electronic device, when it is in the vicinity of an electromagnetic field caused by another electronic device. The origins of EMI are electrical, with the unwanted emissions being either conducted (voltages or currents) or radiated (electric or magnetic fields) $[1,2]$. EMI problems can be reduced at some extent by operating all equipments with a good electrical grounding system. In addition, all cords and cables connecting the peripherals in an electronic system should be shielded from any effects from each other to keep unwanted EM energy from entering or leaving. Biological studies have shown that such EM energy is harmful to a human being depending on the amount of exposure $[3,4]$.

^ Correspondence: patelsm@mail.nplindia.org
So, it becomes necessary for mankind to develop and use the shielding materials in the dense EM environment.

A shielding effectiveness (SE) is used to analyze the shielding properties of materials (also known as shields). The SE is defined as the ratio between the field strength, at a given distance from the source, without the shield interposed and the field strength with the shield interposed [5]. For SE applications, materials with electromagnetic screening capabilities are generally used to attenuate the strength of electromagnetic fields in certain areas. A number of research groups have reported the development of cost effective new materials based on conducting polymers, composites and textiles for a number of reasons to use them as a shield [6-11]. The main objective of such $\mathrm{R} \& \mathrm{D}$ is searching a material with high EM absorption, minimum reflection and simpler production process with easy adaptability for applications. Thus, instead of costly metallic shields, various types of textile materials with special ingredients for SE applications have explored at one end of research [12]. Such textile materials have the advantages of good mechanical properties, like flexibility and lightweight and well-established fabrication processes. Shielding effectiveness for a number of blends basically containing a variety of conductive polymers has been measured in the near-field region with a dual-chamber box and in the far-field with a transmission line fixture but these measurement techniques are complicated and also 
the material used for screening are costly [5]. Far-field shielding efficiencies as high as $70 \mathrm{~dB}$ at $1 \mathrm{GHz}$ has been obtained for polymer blends [13]. Today, a vector network analyzer (VNA) system has been extensively used for reliable and fast measurements of different material properties in coaxial and waveguide sample holders $[14,15]$. The SE value of a material under test can be obtained by two port $S$-parameter measurement i.e. transmission measurement after a full two-port calibration of VNA at microwave frequencies. The difference in the transmission parameters with and without the material sample is termed as a desired $\mathrm{SE}($ in $\mathrm{dB})$ as:

$$
\mathrm{SE}_{\mathrm{dB}}=\left(S_{21 \mathrm{~dB}}^{\prime}-S_{21 \mathrm{~dB}}\right)
$$

where, $S_{21 \mathrm{~dB}}$ is a transmission parameter without a shield and $S_{21 \mathrm{~dB}}^{\prime}$ is the transmission parameter with shield.

For commercialization of a new product, the specifications of the product should be well defined and verified against the standards of the measurement after production level. However, the reliability of the measurement result depends on the method used, environmental conditions, and accuracy of instruments. In addition to intensive research for new shielding materials, there is still an absence of generally accepted standardized methods for measuring the shielding effectiveness with consideration of ISO 17025:2005 and GUM documents [5, 16-18]. This paper contributes to formulate the standardized methods and establishing its link to the SI units for confidence in the measured values. The free-space measurements using the VNA system have verified by standard properties of Teflon and Plaster of Paris sheets [19]. The same facility has been used to characterize the textile samples to study its shielding properties and to explore its application as a possible SE material [20]. This paper presents an approach to estimate the uncertainty in SE measurement for textiles evolved from the establish measurement methods and its results are discussed in detail.

\section{Shielding effectiveness of a textile material}

\subsection{SE evaluation using a free-space method}

The uncertainty in measured $S$-parameter can be derived from the basic Friss formula for free-space transmission method. The power at the receiving antenna, $P_{r}$ is given by,

$$
P_{r}=P_{t} G_{1} G_{2}\left(\frac{\lambda}{4 \pi R}\right)^{2}
$$

where $P_{t}$ is the transmitted power, $G_{1}$ and $G_{2}$ are the gains for antenna 1 and antenna $2, \lambda$ is the operating wavelength, $R$ is the separation between two antennas, respectively.

Equation (2) can be modified in terms of the transmission parameter $\left(S_{21}\right)$ measured by VNA system,

$$
\frac{P_{r}}{P_{t}}=S_{21}^{2}=G_{1} G_{2}\left(\frac{\lambda}{4 \pi R}\right)^{2}
$$

Knowing the measured values of the transmission parameter $S_{21}$ over the measurement range, the product of the gains of the antennas is given as:

$$
G_{1} G_{2}=S_{21}^{2}\left(\frac{4 \pi R}{\lambda}\right)^{2}
$$

Now taking $20 \log _{10}$ of the above equation (4), the $S_{21}^{2}$ will return to $\mathrm{dB}$ value due to the voltage ratio in comparison to $G_{1}$ and $G_{2}$, which are the power ratios. So,

$$
G_{1 \mathrm{~dB}}+G_{2 \mathrm{~dB}}=S_{21 \mathrm{~dB}}+20 \log _{10}\left(\frac{4 \pi R}{\lambda}\right)
$$

or,

$$
S_{21 \mathrm{~dB}}=G_{1 \mathrm{~dB}}+G_{2 \mathrm{~dB}}-20 \log _{10}\left(\frac{4 \pi R}{\lambda}\right)
$$

The uncertainty in $S_{21 \mathrm{~dB}}$ is depending on the uncertainty in each of the measured values and the amount of uncertainty that each measured parameter contributes to the uncertainty is $S_{21}$. Thus, by using the law of propagation of uncertainty [18],

$$
\begin{aligned}
u^{2}\left(S_{21 \mathrm{~dB}}\right)= & \left(\frac{\partial S_{21 \mathrm{~dB}}}{\partial G_{1 \mathrm{~dB}}} u\left(G_{1 \mathrm{~dB}}\right)\right)^{2}+\left(\frac{\partial S_{21 \mathrm{~dB}}}{\partial G_{2 \mathrm{~dB}}} u\left(G_{2 \mathrm{~dB}}\right)\right)^{2} \\
& +\left(\frac{\partial S_{21 \mathrm{~dB}}}{\partial R} u(R)\right)^{2}+\left(\frac{\partial S_{21 \mathrm{~dB}}}{\partial \lambda} u(\lambda)\right)^{2} \cdot(7)
\end{aligned}
$$

If a fabric or a sheet of thickness $t$ is inserted between the antennas, equation (6) will be modified as,

$$
\begin{aligned}
S_{21 \mathrm{~dB}}^{\prime}= & G_{1 \mathrm{~dB}}+G_{2 \mathrm{~dB}}-20 \log _{10}\left(\frac{4 \pi(R-t)}{\lambda}\right) \\
& -20 \log _{10} f\left(\sigma_{t}, \varepsilon_{t}, \mu_{t}, t, \omega\right)
\end{aligned}
$$

where, $\sigma_{t}$ is an electrical conductivity, $\varepsilon_{t}$ is a relative permittivity and $\mu_{t}$ is a relative permeability of textile material, $\omega$ is an angular frequency of the signal applied.

The further description of the function $f\left(\sigma_{t}, \varepsilon_{t}, \mu_{t}, t, \omega\right)$ is left as their impact are being covered by the $S_{21} \mathrm{~dB}$ measurements in two conditions for $\mathrm{SE}$ evaluation and the associated measurement uncertainties instead of extracting dielectric and magnetic properties separately, which is available in details somewhere else $[1,5,21]$. However, uncertainty in measurable $t$ for $f$ will be accounted in uncertainty estimation for $S_{21 \mathrm{~dB}}^{\prime}$.

In a similar fashion as for equation (6), the uncertainty in $S_{21 \mathrm{~dB}}^{\prime}$ based on measurable quantities can be given by,

$$
\begin{aligned}
& u^{2}\left(S_{21 \mathrm{~dB}}^{\prime}\right)=\left(\frac{\partial S_{21 \mathrm{~dB}}^{\prime}}{\partial G_{1 \mathrm{~dB}}} u\left(G_{1 \mathrm{~dB}}\right)\right)^{2}+\left(\frac{\partial S_{21 \mathrm{~dB}}^{\prime}}{\partial G_{2 \mathrm{~dB}}} u\left(G_{2 \mathrm{~dB}}\right)\right)^{2} \\
& +\left(\frac{\partial S_{21 \mathrm{~dB}}^{\prime}}{\partial R} u(R)\right)^{2}+\left(\frac{\partial S_{21 \mathrm{~dB}}^{\prime}}{\partial \lambda} u(\lambda)\right)^{2}+\left(\frac{\partial S_{21 \mathrm{~dB}}^{\prime}}{\partial t} u(t)\right)^{2} .
\end{aligned}
$$


Table 1. Structure properties of textile samples.

\begin{tabular}{|c|c|c|c|c|c|c|}
\hline \multirow[b]{2}{*}{$\begin{array}{l}\text { Sample } \\
\text { No. }\end{array}$} & \multirow[b]{2}{*}{$\begin{array}{l}\text { Textile } \\
\text { material }\end{array}$} & \multicolumn{2}{|c|}{ Yarn density } & \multirow{2}{*}{$\begin{array}{l}\text { Type } \\
\text { of } \\
\text { weave }\end{array}$} & \multirow[b]{2}{*}{$\begin{array}{l}\text { Thickness } \\
t(\mu \mathrm{m})\end{array}$} & \multirow[b]{2}{*}{$\begin{array}{l}\text { Density } \\
\left(\mathrm{kg} / \mathrm{m}^{3}\right)\end{array}$} \\
\hline & & $\begin{array}{c}\text { Warp } \\
\text { (threads } / \mathrm{cm} \text { ) }\end{array}$ & $\begin{array}{c}\text { Weft } \\
\text { (threads/cm) }\end{array}$ & & & \\
\hline Sample $I$ & Cotton/polyester & 37 & 34 & Twill $2 / 1$ & 150.10 & 74.02 \\
\hline Sample $I I$ & Cotton/polyester & 37 & 36 & Twill 2/1 & 155.45 & 98.28 \\
\hline Sample $I I I$ & Cotton/polyester & 37 & 41 & Twill 2/1 & 160.85 & 107.07 \\
\hline
\end{tabular}

Table 2. Electrical properties of textile samples.

\begin{tabular}{cccccccc}
\hline Sample No. & $V_{\mathrm{DC}} / I_{\mathrm{AB}}$ & $V_{\mathrm{BC}} / I_{\mathrm{AD}}$ & $\alpha_{t}$ & $\lambda_{t}$ & $k_{t}$ & $K\left(k_{t}\right) / K\left(k_{t}^{\prime}\right)$ & $R_{y y, \square} / R_{x x, \square}$ \\
\hline Sample $I$ & 0.0035 & 0.0023 & 1.522 & 0.573 & 0.569 & 0.876 & 0.326 \\
Sample $I I$ & 0.0042 & 0.0034 & 1.235 & 0.537 & 0.577 & 0.888 & 0.317 \\
Sample $I I I$ & 0.0051 & 0.0044 & 1.160 & 0.526 & 0.580 & 0.892 & 0.314 \\
\hline
\end{tabular}

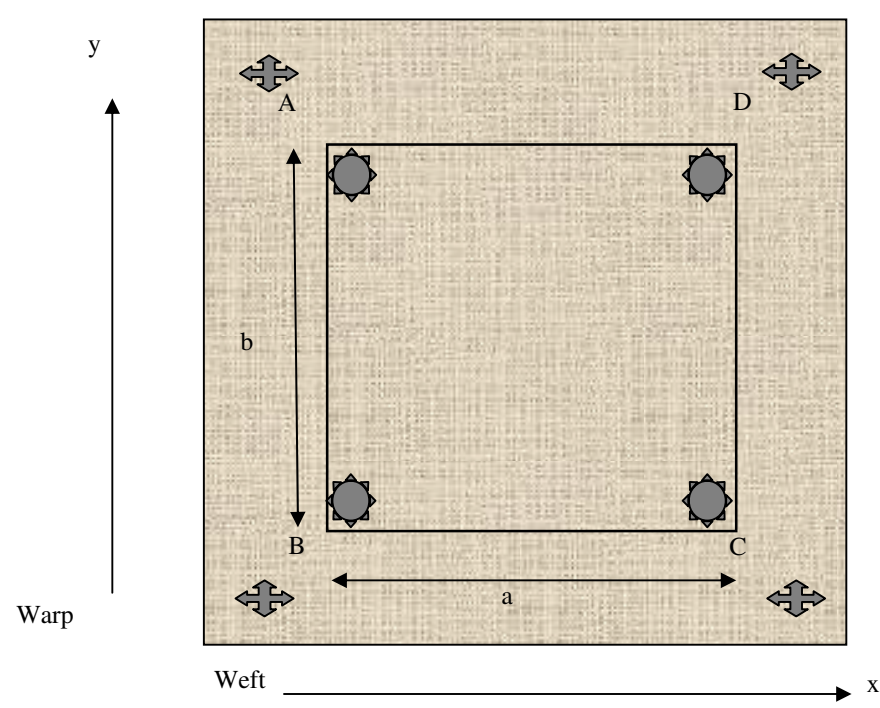

Fig. 1. Arrangement of a textile for structural and electrical properties.

Finally, from equations (1), (7) and (9), we can evaluate the uncertainty in SE values using the quadrature sum of the fractional uncertainties of each parameter. Therefore,

$$
u\left(\mathrm{SE}_{\mathrm{dB}}\right)=\sqrt{u^{2}\left(S_{21 \mathrm{~dB}}^{\prime}\right)+u^{2}\left(S_{21 \mathrm{~dB}}\right)} .
$$

\subsection{Evaluation of textile properties}

Arbitrary textile materials made of cotton and polyester have been taken as samples namely $I, I I$ and $I I I$ and the arrangement of a textile for measurements is shown in Figure 1 . These samples have the different properties and their structural details are given in Table 1. The thickness of the samples has been measured using a calibrated screw gauge in temperature and humidity ranges of $23 \pm 1{ }^{\circ} \mathrm{C}$ and $50 \pm 10 \% \mathrm{RH}$. The weights of textiles were measured with Mass comparator AT 201 make Mettler Toledo to calculate the density.

A Van Der Pauw method is used for the electrical properties of textiles used as described in the previous contribution [22]. We took the textile samples of size $6 \times 6 \mathrm{~cm}^{2}$ and prepared four electrical contacts using the silver paste on the each corner of textile. The electrical conductivity and uniformity of individual contacts were checked and the samples were tightly fixed at the four locations outside the designated area for the measurements. The electrical measurements were performed using Electrometer 6517 and Delta-mode setup 6221/2182A of Keithley make. Table 2 summarizes the evaluated electrical properties of three textile samples. The same expressions and the similar symbols are used as in reference [22] to find an anisotropy ratio, $R_{y y, \square} / R_{x x, \square}$ ratios of two square resistances corresponds to the weft $(x)$ and warp $(y)$ directions.

We have found that the sample III is more dense and least anisotropic compared to other samples. Although, these samples did not have much differences in their structural and electrical properties, their lower anisotropy ratio indicates that the resistivity in the $x$-direction is larger than in the $y$-direction.

\section{SE measurements of textiles}

The free space measurement set up using VNA Wiltron 37247B and two X-band horn antennas is shown in Figure 2 for SE measurements of $90 \times 80 \mathrm{~cm}^{2}$ size of textiles. The value of $R$ is estimated using $2 D^{2} / \lambda$, where $D$ is the average diagonal dimension of two antennas used [19]. However, the wavelengths for the frequencies used in this paper is around $3 \mathrm{~cm}$ (corresponds to $10 \mathrm{GHz}$ ). The present set up was found very sensitive due to EM radiation and so, the various arrangements were made to achieve stable measurements, like least vibration on textiles due to air by proper fixing, no human interference in the measurement area, re-calibrations of the VNA, etc.

The VNA has been calibrated by Thru-Reflect-Line (TRL) calibration technique using the two horn antennas (Ant.1 and Ant.2) employing free space standards [21]. After taking many adjustments and precautions regarding antenna alignments and other radiation or interference effects, we have been able to get the $S_{21}$ less than $0.02 \mathrm{~dB}$ throughout X-band range after full port TRL calibration. After two-port calibration, the transmission parameters without any shield in between two antennas were recorded as set A. Then, the textile sample $I$ has been placed in the 


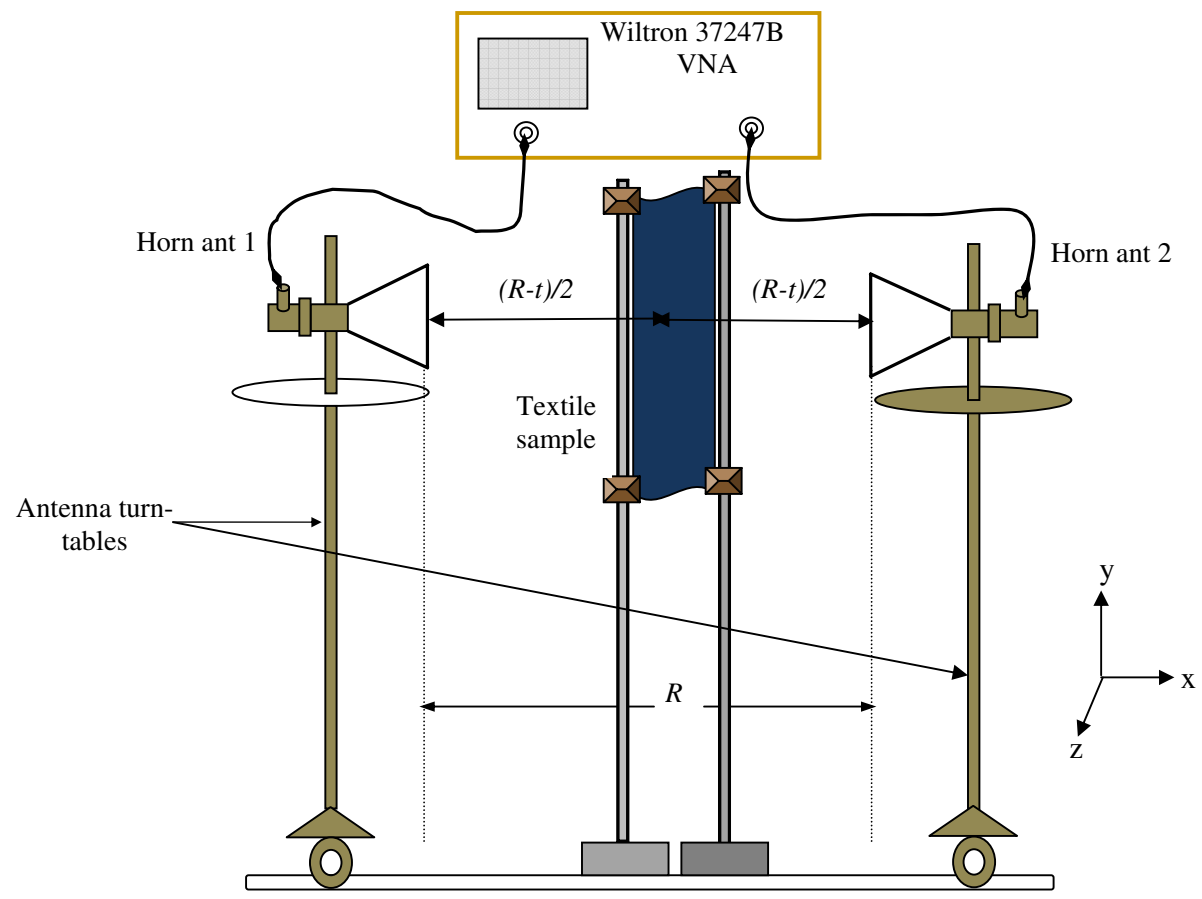

Fig. 2. Schematic diagram of a laboratory developed free-space measurement set up.

Table 3. SE values in $\mathrm{dB}$ of three textile samples.

\begin{tabular}{cccc}
\hline Freq. (GHz)/Sample & Sample & Sample & Sample \\
No. & $I$ & $I I$ & $I I I$ \\
\hline 8.5 & 8.21 & 8.54 & 10.46 \\
9.0 & 8.05 & 8.25 & 9.28 \\
10.0 & 8.26 & 8.16 & 9.32 \\
10.5 & 8.08 & 9.87 & 9.85 \\
11 & 6.51 & 13.65 & 16.24 \\
12 & 9.52 & 8.88 & 9.93 \\
\hline
\end{tabular}

center of the two antennas as shown in Figure 2 and transmission coefficients are again measured respectively and recorded as set $B$. The difference in the recorded transmission coefficients, set $\mathrm{A}$ and $\mathrm{B}$, at each frequency point is the desired SE of the sample $I$ using equation (1). Later on, the measurements are performed for sample $I I$ and sample $I I I$ respectively to evaluate SE values. The evaluated $\mathrm{SE}$ values of the three samples are given in Table 3.

Equations (7), (9) and (10) can be used to estimate the uncertainty in the evaluated SE values using free-space transmission method. To obtain the standard uncertainty in the measured $S_{21}$ due to repeatability, 10 readings have been taken and the Type A uncertainty $\left(u_{a}\right)$ is calculated. The uncertainties due to calibration standards, the operating wavelength $\lambda$ (or frequency) and residual properties of the VNA system have been combined to consider as an uncertainty component $\left(u_{V N A}\right)$ due to VNA system [23]. The effects due to the antennas and adjacent environment on measured $S_{21 \mathrm{~dB}}$ will be normalized by measurements in two conditions for SE evaluation. However, the uncertainties in the antenna gains will be taken into the consideration of uncertainty analysis, which also includes the uncertainties due to mismatch and any interference [20]. Thus, the uncertainty in SE values will depend on the separation between two antennas $R$, thickness of the textile $t$, antenna gains, and the VNA measurement system uncertainties. Equations (7) and (9) may further modify as equations (11) and (12), respectively to represent the measurement model [17].

$$
\begin{aligned}
u^{2}\left(S_{21 \mathrm{~dB}}\right)= & u_{a}^{2}+u_{V N A}^{2}+\left(\frac{\partial S_{21 \mathrm{~dB}}}{\partial G_{1 \mathrm{~dB}}} u\left(G_{1 \mathrm{~dB}}\right)\right)^{2} \\
& +\left(\frac{\partial S_{21 \mathrm{~dB}}}{\partial G_{2 \mathrm{~dB}}} u\left(G_{2 \mathrm{~dB}}\right)\right)^{2}+\left(\frac{\partial S_{21 \mathrm{~dB}}}{\partial R} u(R)\right)^{2} \\
& +\left(\frac{\partial S_{21 \mathrm{~dB}}}{\partial \lambda} u(\lambda)\right)^{2} \\
u^{2}\left(S_{21 \mathrm{~dB}}^{\prime}\right)= & u_{a}^{2}+u_{V N A}^{2}+\left(\frac{\partial S_{21 \mathrm{~dB}}^{\prime}}{\partial G_{1 \mathrm{~dB}}} u\left(G_{1 \mathrm{~dB}}\right)\right)^{2} \\
& +\left(\frac{\partial S_{21 \mathrm{~dB}}^{\prime}}{\partial G_{2 \mathrm{~dB}}} u\left(G_{2 \mathrm{~dB}}\right)\right)^{2}+\left(\frac{\partial S_{21 \mathrm{~dB}}^{\prime}}{\partial R} u(R)\right)^{2} \\
& +\left(\frac{\partial S_{21 \mathrm{~dB}}^{\prime}}{\partial \lambda} u(\lambda)\right)^{2}+\left(\frac{\partial S_{21 \mathrm{~dB}}^{\prime}}{\partial t} u(t)\right)^{2} .
\end{aligned}
$$

Based on this analysis, a traceability link to the national standards of measurements is presented in Figure 3 for the SE measurements of textiles. 


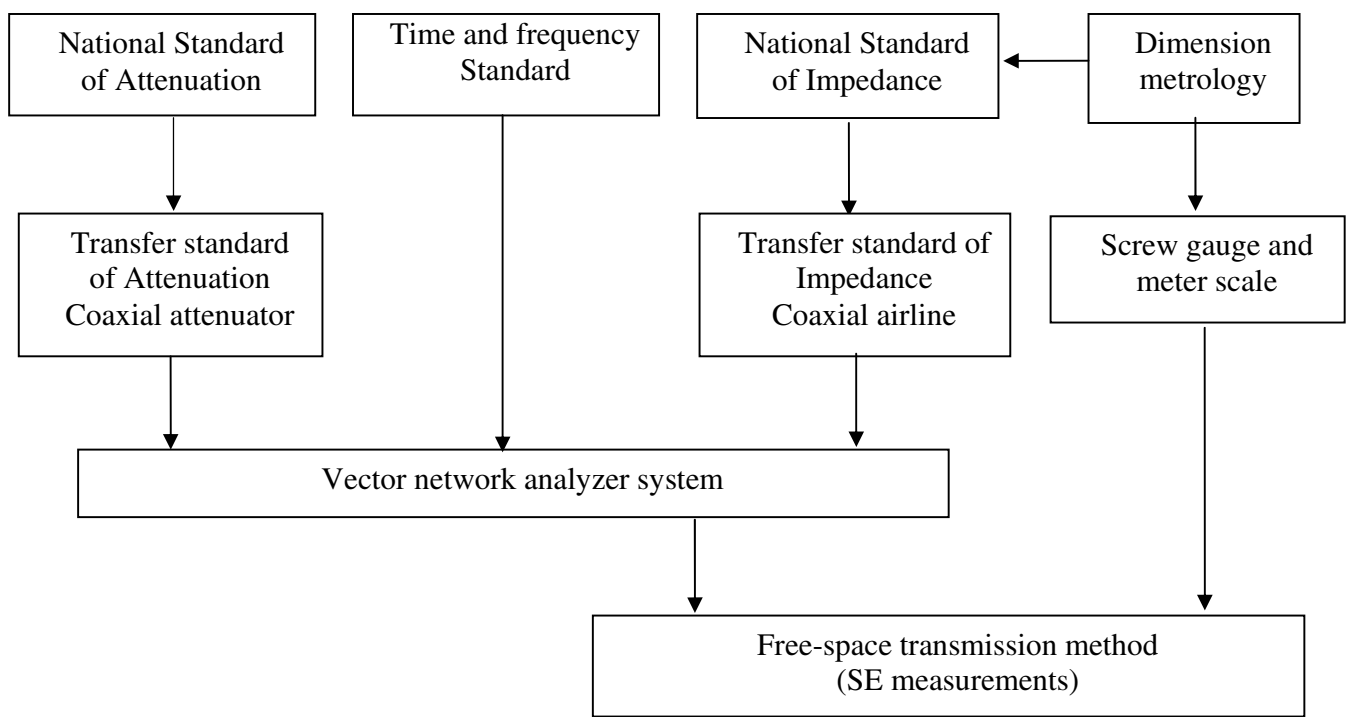

Fig. 3. A traceability link established for SE measurements.

Table 4. Uncertainty budget for sample $I I I$ at $11 \mathrm{GHz}$.

\begin{tabular}{|c|c|c|c|c|c|c|c|}
\hline $\begin{array}{l}\text { Sources of uncertainty } \\
\text { for } S_{21 \mathrm{~dB}}\end{array}$ & $\begin{array}{l}\text { Estimate } \\
\text { of input } \\
\text { quantity }\end{array}$ & $\begin{array}{l}\text { Standard } \\
\text { uncertainty }\end{array}$ & $\begin{array}{c}\text { Probability } \\
\text { distribution/ } \\
\text { Type }\end{array}$ & $\begin{array}{l}\text { Variance } \\
\text { of input } \\
\text { quantity }\end{array}$ & $\begin{array}{c}\text { Sensitivity } \\
\text { coefficient } \\
\text { square }\end{array}$ & \multicolumn{2}{|c|}{$\begin{array}{c}\text { Uncertainty } \\
\text { contribution (dB) }\end{array}$} \\
\hline Repeatability, $u_{a}$ & $0.02 \mathrm{~dB}$ & $0.010 \mathrm{~dB}$ & t/Type A & 0.0032 & 1 & & 0.0032 \\
\hline VNA, $u_{V N A}$ & $0.02 \mathrm{~dB}$ & $0.015 \mathrm{~dB}$ & N/Type B & 0.0075 & 1 & & 0.0075 \\
\hline Antenna gain, $u\left(G_{1}\right)$ & $20.56 \mathrm{~dB}$ & $0.190 \mathrm{~dB}$ & N/Type B & 0.095 & 0.5 & & 0.0475 \\
\hline Antenna gain, $u\left(G_{2}\right)$ & $17.20 \mathrm{~dB}$ & $0.190 \mathrm{~dB}$ & N/Type B & 0.095 & 0.5 & & 0.0475 \\
\hline Meter scale (for $R$ ), $u_{R}$ & $97.5 \mathrm{~cm}$ & $0.090 \mathrm{~cm}$ & R/Type B & 0.052 & 0.05 & & 0.0026 \\
\hline Combined uncertainty $(\mathrm{dB})$ & & & & & & & 0.0677 \\
\hline $\begin{array}{l}\text { Sources of uncertainty } \\
\text { for } S_{21 \mathrm{~dB}}^{\prime}\end{array}$ & $\begin{array}{l}\text { Estimate } \\
\text { of input } \\
\text { quantity }\end{array}$ & $\begin{array}{l}\text { Standard } \\
\text { uncertainty }\end{array}$ & $\begin{array}{r}\text { Probabi } \\
\text { distribut } \\
\text { Type }\end{array}$ & & $\begin{array}{l}\text { iance } \\
\text { nput } \\
\text { ntity }\end{array}$ & $\begin{array}{l}\text { ensitivity } \\
\text { oefficient } \\
\text { square }\end{array}$ & $\begin{array}{c}\text { Uncertainty } \\
\text { contribution } \\
(\mathrm{dB})\end{array}$ \\
\hline Repeatability, $u_{a}$ & $16.24 \mathrm{~dB}$ & $0.050 \mathrm{~dB}$ & t/Type & & 016 & 1 & 0.0160 \\
\hline VNA, $u_{V N A}$ & $16.24 \mathrm{~dB}$ & $0.030 \mathrm{~dB}$ & N/Type & & 015 & 1 & 0.0150 \\
\hline Antenna gain, $u\left(G_{1}\right)$ & $20.56 \mathrm{~dB}$ & $0.190 \mathrm{~dB}$ & N/Type & & 095 & 0.5 & 0.0475 \\
\hline Antenna gain, $u\left(G_{2}\right)$ & $17.20 \mathrm{~dB}$ & $0.190 \mathrm{~dB}$ & N/Type & & 095 & 0.5 & 0.0475 \\
\hline Meter scale (for $R$ ), $u_{R}$ & $97.5 \mathrm{~cm}$ & $0.090 \mathrm{~cm}$ & R/Type & & 052 & 0.578 & 0.0030 \\
\hline Screw gauge (for $t), u_{t}$ & $160.85 \mu \mathrm{m}$ & $0.063 \mu \mathrm{m}$ & R/Тype & & 036 & 0.578 & 0.0210 \\
\hline Combined uncertainty $(\mathrm{dB})$ & & & & & & & 0.0796 \\
\hline $\begin{array}{l}\text { Combined uncertainty }(\mathrm{dB}) \\
\text { in } \mathrm{SE}_{\mathrm{dB}} \text { [equation (10)] }\end{array}$ & & & & & & & 0.1045 \\
\hline Expanded uncertainty (dB) & & & t coverage fact & or $k=2$ & & & 0.2089 \\
\hline
\end{tabular}

\section{Results and discussions}

An uncertainty budget is prepared for SE values using the measured $S_{21 \mathrm{~dB}}^{\prime}$ and $S_{21 \mathrm{~dB}}$ values based on equations (10), (11) and (12) and is given as a Table 4 for sample III. The term 'Uncertainty contribution' represents the uncertainty in each parameter or source and the individual contribution on measured $S_{21}$.

The uncertainties in SE values of other samples have been obtained at the different frequencies in X-band range according to Table 4 . The $\mathrm{SE}$ values of three samples have shown along with expanded uncertainties against frequency in Figure 4.
Interestingly, the $\mathrm{SE}$ values of the samples have quite different responses in X-band even though made of the same kind of fabric. The least dense sample $I$ produced SE in the range of 6-9 $\mathrm{dB}$ whereas comparatively more dense sample $I I$ and sample $I I I$ have $\mathrm{SE}$ values in the range of 8-13 $\mathrm{dB}$ and 9-16.24 $\mathrm{dB}$ respectively. Also the sample $I I$ and sample $I I I$ have shown similar patterns and SE values due to their similar characteristics, the difference may be observed due to thickness variation. However, the maximum SE value is found $16.24 \pm 0.21 \mathrm{~dB}$ at $11 \mathrm{GHz}$ for the sample III. Values at $8.2 \mathrm{GHz}$ and $12 \mathrm{GHz}$ are less reliable as calibration may not be accurate at the end frequencies compared to the center frequency by free-space 


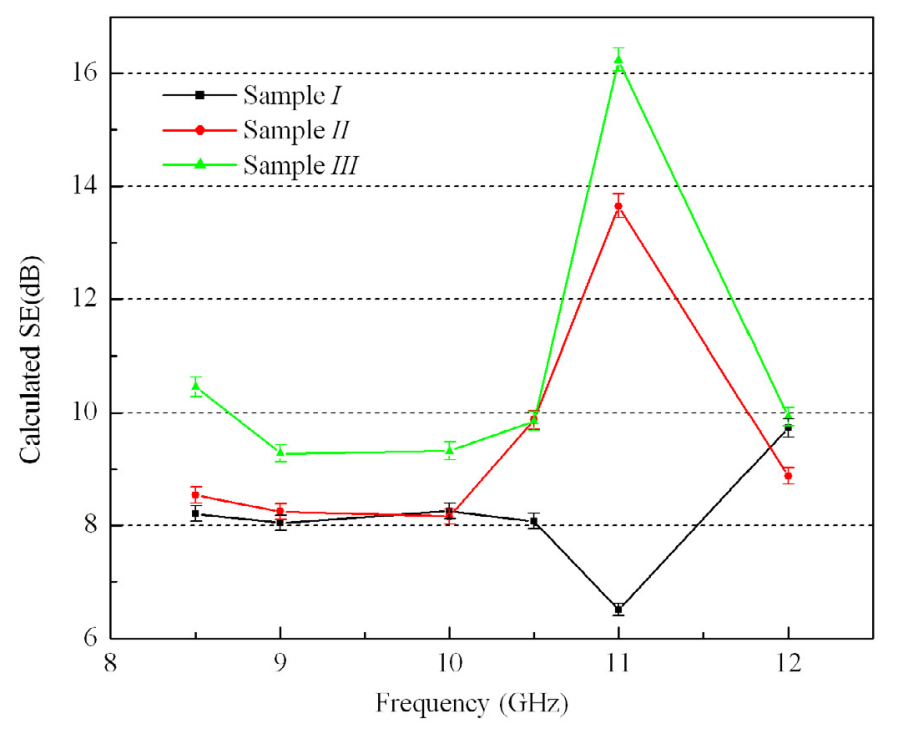

Fig. 4. The SE values of textiles along with the expanded uncertainties.

standards. In overall, the higher SE values are found with thickest and least anisotropic material (sample III) as the samples have about $5 \mu \mathrm{m}$ differences in their thicknesses and square resistances. The presence of evaluated SE in these textiles is predicted mainly due to the reflection than the absorption and this phenomenon can be validated by the measurement of dielectric constant [5]. Variation in the dielectric constant and resonance behavior due to the relaxation time of the dipoles present in samples would have been the sources of the gradual changes in SE over the frequency range. As the textiles are heterogeneous mixture of fibre and air, highly dense textile has provided higher SE compared to the other textiles due to the dielectric resonance at $11 \mathrm{GHz}$ [12]. In addition, this resonance may depend on the yarn density and thickness, as sample $I$ has revealed opposite behavior than samples $I I$ and $I I I$ in the measurement frequency range. Further study is required to verify this aspect; however, we have been able to show that these textile materials possess significant shielding efficiencies without any modification in their structure.

\section{Conclusions}

The present paper describes a simple laboratory established method for evaluating shielding properties of textiles, which is based on free space using VNA along with expressions for estimating uncertainties in SE values. It has been found that the SE values of textiles mainly depend on its intrinsic properties, frequency range and thickness. The results demonstrated that the textile material with high density would have higher SE and increases with thickness due to dielectric absorption. The uncertainty budget is presented for SE from combined uncertainties in two $S_{21}$ measurements and given to standardize the type of measurement and system with a scope of further modification. Thus, a simple textile material can be modified to design special apron like garments for applications under the area of electromagnetic exposures. In the practical examples like, while using microwave ovens or taking high power RF and microwave measurements, etc., an operator can easily wear the clothes made of such EM shielding fabric. Thus the present study has encouraged the development of new textile materials for EM energy shielding purpose and presented a valid measurement system to apply on different kind of fabrics for study. However, the other effects like, light intensity, colour, temperature and performance at other frequency bands are yet to study simultaneously on such textile for supporting their wide applications as a shielding. The future work will be to modify the existing materials in order to re-define their parameters and compare them with other materials for evaluating the effect of the implemented modifications. The improvements are also possible in the design of the weave and yarn density in order to have a uniform relaxation time and optimized inter-facial polarization suited to the frequency range of interest for such shielding textile.

Acknowledgements. The present work performed under CSIRnetwork project \#NWP-045 in establishing precise measurement techniques. The authors like to thank Prof. R.C. Budhani, Director NPL, and the respective Department Heads at NPL, for their keen interest and support of the work.

\section{References}

1. C.R. Paul, Introduction to Electromagnetic Compatibility (Wiley Interscience, 2006)

2. M.A. Stuchly, Electromagnetic fields and health, IEEE Potentials 12, 34-39 (1993)

3. R.W. Habash, Electromagnetic - the uncertain health risks, IEEE Potentials 22, 23-26 (2003)

4. NIEHS Report on Health Effects from Exposure to Powerline Frequency Electric and Magnetic Fields, National Institute of Health, NC 27709, NIEHS (1999)

5. Tadeusz W. Więckowski, Janukiewicz M. Jarosław, Methods for evaluating the shielding effectiveness of textiles, Fibres Textiles Eastern Europe 14, 18-22 (2006)

6. L.O. Hoeft, E.W. Tokarsky, Measured electromagnetic shielding characteristics of fabric made from Metal Clad Aramid Yarn and Wire, in Proceedings of IEEE International Symposium in EMC, Washington DC, USA, 2000, Vol. 2, pp. 883-886

7. M.R. Anantharaman, S. Sindhu, S. Jagatheesan, K.A. Malini, P. Kurian, Dielectric properties of rubber ferrite composites containing mixed ferrites, J. Phys. D 32, 18011810 (1999)

8. Hongtao Guan, Shunhua Liu, Yuping Duan, Ji Cheng, Cement based eletromagnetic shielding and absorbing building materials, Cem. Conc. Comp. 28, 468-474 (2006)

9. K.B. Cheng, S. Ramakrishna, K.C. Lee, Electromagnetic shielding effectiveness of copper/glass fiber knitted fabric reinforced polypropylene composites, Composites: Part A 31, 1039-1045 (2000) 
10. J.D. Sudha, S. Sivakala, K. Patel, P. Radhakrishnan Nair, Development of electromagnetic shielding materials from the conductive blends of polystyrene polyaniline-clay nanocomposite, Composites: Part A 41, 1647-1652 (2010)

11. V.K. Sachdev, K. Patel, S. Bhattacharya, R.P. Tandon, Electromagnetic interference shielding of graphite/acrylonitrile butadiene styrene composites, J. Appl. Polymer Sci. 120, 1100-1105 (2011)

12. K. Bal, V.K. Kothari, Measurement of dielectric properties of textile materials and their applications, Indian J. Fibre Text. Res. 34, 191-199 (2009)

13. N.F. Colaneri, L.W. Shacklette, EMI shielding measurements of conductive polymer blends, IEEE Trans. Inst. Meas. 41, 291-297 (1992)

14. S.M. Shajedul Hasan, Madhan Sundaram, Yoon Kang, Mostofa K. Howlader, Measurement of dielectric properties of materials using the transmission/reflection method with material filled transmission line, in Proceedings of IMTC 2005 - Instrumentation and Measurement Technology Conference, Ottawa, Canada, 2005, pp. 17-19

15. D.K. Ghodgaonkar, V.V. Varadan, V.K. Varadan, Freespace measurement of complex permittivity and complex permeability of magnetic materials at microwave frequencies, IEEE Trans. Inst. Meas. 39, 387-394 (1990)

16. ASTM - D4935, Standard Test Method for Measuring the Electromagnetic Shielding Effectiveness of Planar Materials (1999)
17. ISO/IEC 17025: 2005, General requirements for the competence of testing and calibration laboratories (2005)

18. ISO/IEC Guide 98:1995, Guide to the expression of uncertainty in measurement (GUM, 1995)

19. K. Patel, S.M. Patel, P.S. Negi, Performance of VNA based free-space method for the complete dielectric property characterization, Invertis J. Sci. Technol. 5, 33-39 (2012)

20. S.M. Patel, K. Patel, P.S. Negi, V.N. Ojha, Characterization of different types of materials for their shielding effectiveness, in Proceedings of National Conference on Emerging Technologies and Applications, Jaipur, India, 2010

21. S. Brzeziński, T. Rybicki, G. Malinowska, I. Karbownik, E. Rybicki, Lech Szugajew, Effectiveness of Shielding Electromagnetic Radiation, and Assumptions for Designing the Multi-layer Structures of Textile Shielding Materials, Fibres Textiles Eastern Europe 17, 60-65 (2009)

22. I. Kazani, G. De Mey, C. Hertleer, J. Banaszczyk, A. Schwarz, G. Guxho, L. Van Langenhove, Van Der Pauw method for measuring resistivities of anisotropic layers printed on textile syubstrates, Text. Res. J. 81, 2117-2124 (2011)

23. K. Patel, P.S. Negi, Estimation of Complex and Linear Uncertainties in $S$-Parameter Measurements for Metrology Applications, Int. J. Electromagn. Appl. 2, 85-104 (2012) 